(c) VMS RESEARCH FOUNDATION www.ijrbat.in

\title{
ROLE OF NANOTECHNOLOGY IN AGICULTURE AND FOOD INDUSTRY
}

\author{
Sunil M. Chore
}

Hshivramji Moghe Arts Commerce and Science College, Kelapur

Communicated: 27.07 .19
Published: 30.09 .2020

\begin{abstract}
:
The word "Nano" is used for very small particles which size is $10^{-9}$ meter. So particles have unique physicochemical properties - large surface area, more reactivity, being more absorbed, etc. Nanotechnology is applied in many industries, medicines, electronics and others enhanced the interesting in agricultural applications. More than 10 percent of agricultural applications of nanotechnology are foods, beverages and food packaging products the effects of metals and metal oxides on plant growth and development as well as their mechanisms in plants. Nanofertilizers industry, bio-production of energy, purification of water, control and treatment of plant diseases. This informative paper suggests need to pay attention to knowledge about nanotechnology in agriculture and food industry; benefits in plant growth. relationships between properties of nanomaterials and biological interactions.
\end{abstract}

Key words: - Nanotechnology, Agriculture, food industry.

\section{Application of Nonherbicide:}

As recent reports indicate that weeds have the potential to devastate the total harvest in the delicate agro-ecosystems. At present, Herbicides in the market are are able to control or kill the above ground part of the weed plants, not below ground plant parts, which are source of new weeds. The use of nano herbicides can solve the problem with deep penetration effect due to nano size particles.

Currently available nonherbicides are not up to the mark researchers have challenge to meet the requirements for best result.

\section{Application of Nano pesticide}

In order a nanotechnology approach, namely "Nano-encapsulation" is the beneficial way to improve the insecticidal value to keep safe the active ingredient from the adverse conditions, by sealing a thin-walled sac or shell (protective coating).

- Nano-pesticides will decrease the rate of application because of nano size particles the effective part will increase with respect to quantity at least $20 \%$ less than the present formulations, with better result. Pesticide industries are producing with nanomaterial.

\section{Application of Nanofood}

Food industries with nanotechnology has been really blessed in a number of food and food packaging products. At present, more than 250 nanofood products available in the global market. The increase of $\mathrm{R} \& \mathrm{D}$ investments in nanofood industries shows eagerness to introduce smart nanofood. The effect of nanotechnology is vast, from basic food to food processing, from value added nutrition to intelligent food packaging the nanotechnology and nanomaterial will cover almost $60 \%$ of food industries in coming decade. Nanofood will be totally different in texture, taste, flavour and colour with additional nutritional value Nanotechnology extends its applications in fruits, vegetables, and flowers. 
I J R B A T, Issue (VIII), Vol. III, Sept 2020: 162-163

A Double-Blind Peer Reviewed \& Refereed Journal

\section{Nanotechnology and Food Processing}

The application of Nanotechnology in food sector includes: smart packaging, preservation, an interactive food etc. The nano-capsules with added nutritional elements and flavour or colour enhancers is dormant in the food.

A modified nanocomposite coating improves food packing by placing by applying antimicrobial material on the surface of the coated film. Nanocomposites control gas permeability of different fillers according to different products.

\section{REFRENCES:}

Kirwan, M. J., and Strawbridge, J. W., (2003). Plastics in food packaging. Food Packaging Technology, 174-240.

Lopez-Rubio, A., R. Gavara and J. M. Lagaron., (2006). Bioactive packaging: turning foods into healthier foods through biomaterials. Trends Food Sci. Technol. 17:567-575.

Nickols-Richardson, S.M. and Piehowski, K.E., (2008). Nanotechnology in nutritional sciences. Minerva Biotechnol, 20, 17126.

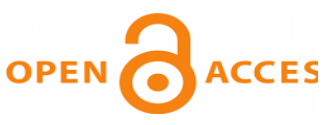

e-ISSN $2347-517 X$

Original Article
Sorrentino, A., G. Gorrasi, and V. Vittoria. 2007. Potential perspectives of bio anocomposites for food packaging applications. Trends in Food Science \& Technology. $18 \quad$ (2):84-95. doi: $10.1016 /$ j.tifs.2006.09.004.

Sekhon, Bhupinder S. 2010. "Food nanotechnology - an overview. Nanotechnology, Science and Applications 3:1-15.

Ochsner, Andreas, Waqar Ahmed, and Nasar Ali. 2009. Nanocomposite Coatings and Nanocomposite Materials: Trans Tech Publications.

Dingman, Jim. 2008. Nanotechnology: Its Impact on Food Safety. Journal of Environmental Health. 70 (6):47-50.

ENVIRONMENTAL PROTECTION AGENCY. Agriculture: Nutrients and Fertilizers.

3.8.2016. Available at https://www.epa.gov/agriculture/agriculture-nutrient-management-and-fertilizer http://www.epa.gov/agriculture/tfer.html Accessed 28.9.2016. 